\title{
Multi-source forcing effects analysis using Liang-Kleeman information flow method and the community atmosphere model (CAM4.0)
}

\author{
ShunYu Jiang ${ }^{1} \cdot$ HaiBo Hu$^{1,3}$ (I) $\cdot$ Ning Zhang ${ }^{1} \cdot$ LiPing Lei $^{2} \cdot$ HaoKun Bai $^{1}$
}

Received: 21 February 2019 / Accepted: 24 July 2019 / Published online: 2 August 2019

(c) The Author(s) 2019

\begin{abstract}
To understand the individual influences of the land cover, sea temperature, sea ice and carbon dioxide concentration on the global climate, sensitive experiments using the General Atmospheric Circulation Model 4.0 are designed to compare with the observation in this study. Firstly, through the analysis of Liang-Kleeman information flow method, it is straightforward that the pronounced causal relationships exist from these forcing to air temperature. In numerical experiments, the temperature is influenced by the albedo and atmospheric dynamic process. More detailed, in winter, the changes of each forcing will cause the positive Pacific-North American Pattern (PNA) phase, which makes the North American colder. The negative North Atlantic Oscillation (NAO) phase caused by the changes of $\mathrm{CO}_{2}$ and sea ice induces cold winter over the Europe. This coincides with the extreme cold weather in Europe and North America in 2018. Whereas in summer, all forcings cause positive Arctic Oscillation (AO) phase, resulting in the most northern hemisphere warmer. It is noteworthy that for precipitation, the changes of each forcing increase winds from the sea surface to the land in East Asia, so the precipitable water increases, thus the precipitation overall increases. However, when $\mathrm{CO}_{2}$ changes, the precipitation decreases due to the lack of dynamic conditions in some areas.
\end{abstract}

Keywords Multi-source forcing $\cdot$ The Liang-Kleeman information flow $\cdot$ CAM4.0 $\cdot$ Temperature change $\cdot$ Atmospheric teleconnection · East Asian precipitation

\section{Introduction}

The changes in land cover types, $\mathrm{CO}_{2}$ concentration, sea surface temperature (SST) and sea ice all have impacts on global climate. Among them, greenhouse gases and global warming are undoubtedly hot topics. Among the several important greenhouse gases $\left(\mathrm{CH}_{4}, \mathrm{CO}_{2}, \mathrm{~N}_{2} \mathrm{O}\right), \mathrm{CO}_{2}$ has the largest contribution to the greenhouse effect and can reach as much as $60 \%$ (IPCC report 2000). Observations show that

HaiBo $\mathrm{Hu}$

huhaibo@nju.edu.cn

1 CMA-NJU Joint Laboratory for Climate Prediction Studies, School of Atmospheric Science, Instituted for Climate and Global Change Research, Nanjing University, Nanjing 210093, China

2 Key Laboratory of Digital Earth Science, Institute of Remote Sensing and Digital Earth, Chinese Academy of Sciences, Beijing 100094, China

3 KLME \& CIC-FEMD, Nanjing University of Information Science and Technology, Nanjing, China with the acceleration of industrialization, $\mathrm{CO}_{2}$ concentration in the atmosphere has increased year by year. Before the industrial revolution, the $\mathrm{CO}_{2}$ in the atmosphere was about $290 \mathrm{ppm}$, while in 1983 it had increased to $342 \mathrm{ppm}$ (Rotty 1983). In 2015, data from multiple atmospheric stations showed that the concentration of $\mathrm{CO}_{2}$ in the atmosphere has exceeded $400 \mathrm{ppm}$. Since the twentieth century, the rising trend of the man-made $\mathrm{CO}_{2}$ emissions has been almost linear (Idso 1983). The main reason for this is the burning of fossil fuels, such as coal and petroleum. On the other hand, deforestation (mainly in tropical forest areas) and the expansion of cultivated land have become the second source of the increase of $\mathrm{CO}_{2}$ in the atmosphere (Woodwell et al. 1978). The clear majority of viewpoints believe that the increase of $\mathrm{CO}_{2}$ will cause climate warming. Doubling the concentration of $\mathrm{CO}_{2}$ can make the equatorial temperature rising by $2-3{ }^{\circ} \mathrm{C}$, and the polar temperature rising by $8{ }^{\circ} \mathrm{C}$ (Manabe and Wetherald 1980). At the same time, the increase of $\mathrm{CO}_{2}$ also affects the distribution of water in different regions. For instance, in the northern hemisphere, when carbon dioxide doubles, the snowmelt period ends earlier, and the 
low precipitation period appears earlier. Simultaneously, the precipitation decreases in the spring and summer in the mid-latitudes, and the soil water content in the middle and high latitudes of the summer decreases sharply, the area between 37 and $45^{\circ} \mathrm{N}$ will become the driest region in the world (Manabe et al. 1981).

Under the background of global warming, the global average SST also increases. It was $16.8{ }^{\circ} \mathrm{C}$ in 2015 that was $0.4{ }^{\circ} \mathrm{C}$ higher than it was in 1961-1990 (Lim et al. 2016). SST anomalies will influence the general circulation, and then affect monsoons and precipitation (Yang et al. 2007). Fundamentally, one of the reasons for the formation and maintenance of atmospheric circulation is the uneven heating of the atmosphere from the equator to the polar region. As early as last century, the study of SST anomalies in the equatorial central and eastern Pacific confirmed that tropical air-sea interactions play an important role in the evolution of global long-term climate processes (Bjerknes 1966; Keshavamurty 1982). Their impact is not limited to low-latitude regions, but also can influence global weather and climate through atmospheric teleconnections (Namias et al. 1988; Wang et al. 2000; Alexander et al. 2001). The Pacific air-sea system has both interannual signals (such as ENSO) and interdecadal variabilities, such as the Pacific Decadal Oscillation (PDO) (Rasmusson and Wallace 1983; Ropelewski and Halpert 1987; Trenberth 1990; Wu et al. 2005; Pavia et al. 2006). Many studies have shown that PDO has a significant impact on Pacific and North American climates (Zhang et al. 1997; Latif and Barnett 1994; Bond and Harrison 2000), which is also closely related to the atmospheric circulation in East Asia and the interdecadal climate change in China. What's more, hiatus is an important scientific issue in recent years to explore climate change, and studies had shown that a large amount of heat entering the deep sea is the main cause (Meehl et al. 2013; Balmaseda et al. 2013; Watanabe et al. 2013). During the period of hiatus, the heat mainly gets into the deep layers of the Atlantic and Southern Oceans, the middle and deep layers of the Pacific and Indian Oceans (Meehl et al. 2011). In addition, the influence of the SST in the Indian Ocean has also become a research hotspot (Chambers et al. 1999; Guan and Yamagata 2003; Zhan et al. 2011). Li et al. (2008) in his study proved that the Indian Ocean warming forced an anticyclonic anomaly in the subtropical western Pacific, enhancing the East Asian summer monsoon.

Sea ice is a cold source of global climate change, the anomalies of which will change the intensity of the polar cold source, then affect the climate. As the interface between the upper part of the ocean and the lower part of the atmosphere, sea ice changes the radiation and energy balance of the ocean surface. Some studies suggest that the interannual variation of sea ice area is caused by anomalies in the atmospheric circulation (Parkinson et al. 1999; Rogers and
Loon 1979). Herman and Johnson (1978) emphasized the sea ice can influence climate through the fast process of atmospheric circulation adjustment and the slow process of ocean adjustment. Firstly, sea ice variation causes a significant change in atmospheric temperature and sea level pressure, and then affects the middle and low latitudes through interactions between the atmospheres. Arctic sea ice cover influences the phase and intensity of the North Atlantic Oscillation (NAO) and Arctic Oscillation (AO) (Liu and Yin 2001), thereby influences the transport of polar cold air to mid-latitudes and directly affects the mid-high latitudes of Eurasia. In the past few decades, the thickness of the Arctic sea ice has become thinner and the area decreased, and the AO has continued to enhance. On the contrary, the Antarctic sea ice is growing (Comiso and Nishio 2008), which has greater freedom of movement than the Arctic and has an impact on atmospheric stability and precipitation in the Antarctic region (King and Turner 1997).

Recent studies have pointed out that the changes in land use also have significant impacts on the climate. On the one hand, the land use directly influences vegetation type and physical characteristics of the land surface, which in turn affect the exchange of radiation, heat, and water vapor. On the other hand, it will change the population distribution, which can cause changes in terrestrial carbon storage and its flux, then influences the climate. As early as the 1970s, Charney (1975), Charney et al. (1977) found that there is a positive feedback mechanism between surface albedo and aridity, and then studied the effect of surface albedo changes on the degree of drought in semi-arid areas. The land use changes the physical characteristics of the Earth's surface and thus causes climate changing. Therefore, many parameters have been defined to represent the physical characteristics, such as the leaf area index (Chase et al. 1996), the surface roughness (Sud and Smith 1985), the stomatal conductance (Hendersonsellers et al. 1995) and so on. Later, studies have shown that land use can also affect the climate by influencing greenhouse gas emissions (Houghton et al. 1983). What's more, it changes the balance of surface energy and moisture by affecting near-surface temperature and precipitation (Bright et al. 2012). Fang (2013) believed that the conversion from forest to pasture and farmland reduced the flux of water and latent heat from the surface to the atmosphere, resulting in an increase in surface temperature. In fact, the effects of radiation caused by changes in the albedo and hydrological cycle caused by the water balance often have the opposite effect on the surface temperature. For example, large-scale deforestation leads to an increase in the surface albedo and thus the surface temperature decreases. From the point of water balance, the reduction in transpiration plays a role in warming (Bonan 2008). In addition, the climatic effects of forest areas at different latitudes are different. Deforestation of tropical forests may lead to anomalies in 
Rossby waves, affecting climates in high latitudes through teleconnections (Chase et al. 2000). In the high latitudes, deforestation mainly reduces the albedo and thus the regional temperature decreases (Bonan et al. 1992; Brovkin et al. 1999; Govindasamy et al. 2000). For temperate zones between the tropics and high latitudes, its impact on the climate is highly uncertain (Bonan 1999; Snyder et al. 2004).

Land cover, SST, cryosphere and carbon dioxide concentration all have impacts on the global climate. However, direct observations, which include the uncertain climate effects of all these forcings, cannot separate the climate effects produced by each forcing. In addition, many climate change studies emphasize carbon dioxide as the main forcing that affects climate change (Ban-Weiss and Caldeira 2010; Friedlingstein 2014; Seneviratne et al. 2016). But for the atmosphere, in addition to changes in carbon dioxide, SST, land cover and sea ice cover all have significant changes, and these changes have stored and indirectly released the climate impact of carbon dioxide. To study their respective climatic effects, this paper will use the Liang-Kleeman information flow method to give the causal relationship from different forcings to global temperature. And then the CAM4.0 (the Community Atmosphere Model 4.0) is used to set up several experiments (see Sect. 2 for specific experiment settings) to analyze the climate effects of multi-source forcing. The following are the section arrangements of this paper: Sect. 2, describes the data and method, gives the causal relationship from land use, carbon dioxide concentration, SST, sea ice to temperature through the Liang-Kleeman information flow method, and shows the experimental setup; Sect. 3, analyzes the climatic effects of different forcings in numerical experiments; Sect. 4, summarizes and discusses.

\section{Data and method}

\subsection{Data introduction}

The SST and sea ice data used in this paper are OISST monthly data of NOAA, and the horizontal resolution is $1^{\circ} \times 1^{\circ}$, from December 1981 to December 2017 (Reynolds et al. 2002). The NDVI (Normalized Difference Vegetation Index) is obtained by a combination of red band and nearinfrared band (Tucker 1979). It is the most widely used and highly correlated with biomass, chlorophyll content, energy absorption and so on (Cracknell 2001). NDVI is an effective parameter for characterizing land cover changes, and many scholars have studied the relationship between the change of climatic factors (mainly precipitation, temperature) and NDVI (Defries and Townshend 1994; Pettorelli et al. 2005). Therefore, we used the Normalized Difference Vegetation Index(NDVI) to represent land cover when we performed the analyses. The NDVI (Normalized Difference Vegetation
Index) is monthly average data with a horizontal resolution of $1 / 12^{\circ} \times 1 / 12^{\circ}$ from 1981 to 2015 , which is available from ECOCAST. $\mathrm{CO}_{2}$ data from the fusion of three satellite data (Crisp 2004; Reuter et al. 2011; Crisp et al. 2012; Belikov et al. 2014), the space-time resolution is 8 days, the horizontal resolution is $1^{\circ} \times 1^{\circ}$, of which 2003.01.08-2009.05.30 from SCIAMACHY-XCO2, the data accuracy is $2.5 \mathrm{ppm}$; 2009.06.01-2014.08.30 from GOSAT-XCO2. Among them, 2009.06.01-2014.06.30 is based on ACOS algorithm, the accuracy is $1 \mathrm{ppm}$, and 2014.07.01-2014.08.30 is based on NIES algorithm, the accuracy is about $2 \mathrm{ppm}$; 2014.09.01-2016.03.25 from $\mathrm{OCO}_{2}-\mathrm{XCO}_{2}$, the accuracy is $0.5 \mathrm{ppm}$. The monthly $\mathrm{CO}_{2}$ data is available from $\mathrm{CO}_{2}$ earth. The temperature data is monthly surface temperature from NCEP/NCAR reanalysis data, and the horizontal resolution is $2.5^{\circ} \times 2.5^{\circ}$, from January 1948 to December 2017 . The data analyzed with $\mathrm{CO}_{2}$ is the daily surface temperature of the reanalysis data, and the disposal is 8 days average with a time of 2003.1.8-2016.3.25. The precipitation data is monthly data of NOAA from 1948 to 2017 with a horizontal resolution of $2.5^{\circ} \times 2.5^{\circ}$.

\subsection{Liang-Kleeman information flow and time series causal analysis}

Given two time series, can we tell which is the cause and which is the effect, or do the two cause and effect each other? Causal analysis is undoubtedly very important in different disciplines, but it is also a famous problem. In fact, it has been called one of the biggest challenges in big data science. In recent years, Liang (2014) has made a breakthrough in this issue using the Liang-Kleeman information flow theory. For linear systems, given two time series of $X_{1}$ and $X_{2}$, Liang proves that the maximum likelihood estimator (mle) of information flowing from $X_{2}$ to $X_{1}$ per unit time is

$\hat{T}_{2 \rightarrow 1}=\frac{C_{11} C_{12} C_{2, d 1}-C_{12}^{2} C_{1, d 1}}{C_{11}^{2} C_{22}-C_{11} C_{12}^{2}}$

where $C_{i j}$ is the sample covariance between $X_{i}$ and $X_{j}$, $C_{i j}:=\overline{\left(X_{i}-\bar{X}_{i}\right)\left(X_{j}-\bar{X}_{j}\right)}$.

$\mathrm{C}_{i, d j}$ is the sample covariance between $X_{i}$ and a series derived from $X_{j}$ using the Euler forward differencing scheme, $\dot{X}_{j, n}=\frac{X_{j, n+k}-X_{j, n}}{k \Delta t}, \Delta \mathrm{t}$ is the time step and $\mathrm{k} \geq 1$ (integer). The flow in the opposite direction $T_{1 \rightarrow 2}$ can be directly written by switching indicators 1 and 2 . The units are in nats per unit time. The above equation (Eq. 1) may also be written in terms of linear correlation coefficients (Liang 2014). Here is the corollary: in the liner sense, causation implies correlation, but correlation does not imply causation (Liang 2016). Information flow is considered a measure of causality, and 
the exchange between two events as information not only indicates the quantity, but also indicates the direction of the causal relationship (Liang 2015). Ideally if $T_{2 \rightarrow 1}=0$, $X_{2}$ does not cause $X_{1}$; if it is not equal to zero (either positive or negative), it is causal. In practice, however, statistical significance test must be performed to see whether $T_{2 \rightarrow 1}$ is significantly different from zero. There is a proven theorem (Liang 2016) (principle of nil causality): if the development of $X_{1}$ is independent of $X_{2}$, the flow of information from $X_{2}$ to $X_{1}$ is zero. The formalism bridges the gap between theory and real applications, and has been put to application with success to real world problems, such as the research on the relationship between carbon dioxide and global warming (Liang 2013; Stips et al. 2016; Liang 2018).

Through the result of the Liang-Kleeman information flow, some conclusions are obtained. There is a clear causal link from the forcings (SST, sea ice, land cove, carbon dioxide) to the air temperature. The large information flow area of sea ice to air temperature is mainly located at the edge of the sea ice, where the sea ice changes most strongly (Fig. 1b). In land cover analysis, the NDVI (Normalized
Difference Vegetation Index) is used to represent land cover. The result shows that the information flow in Asia, Europe and North America is more obvious, which means land cover change has a greater impact on climate in these regions. The $\mathrm{CO}_{2}$ grid data we used only covers the land, so we analyzed the causality from the $\mathrm{CO}_{2}$ of each grid point to the global average temperature to avoiding the error caused by the lack of the data in sea surface. In the result of carbon dioxide, there is a significant information flow in Eurasia and North America. The information flow from $\mathrm{CO}_{2}$ to air temperature is smaller than that of other forings, and this may be because carbon dioxide influences temperature more slowly than other forcings. We identified several key areas from the results of causal analysis: the sea ice edge (sea ice); Eurasia and North America (land cover and $\mathrm{CO}_{2}$ ). Therefore, the model simulations are carried out to verify whether there are more pronounced and attractive climate effects in these key areas. In addition, when analyzing simulation results, we focus on the climate change in these key areas.
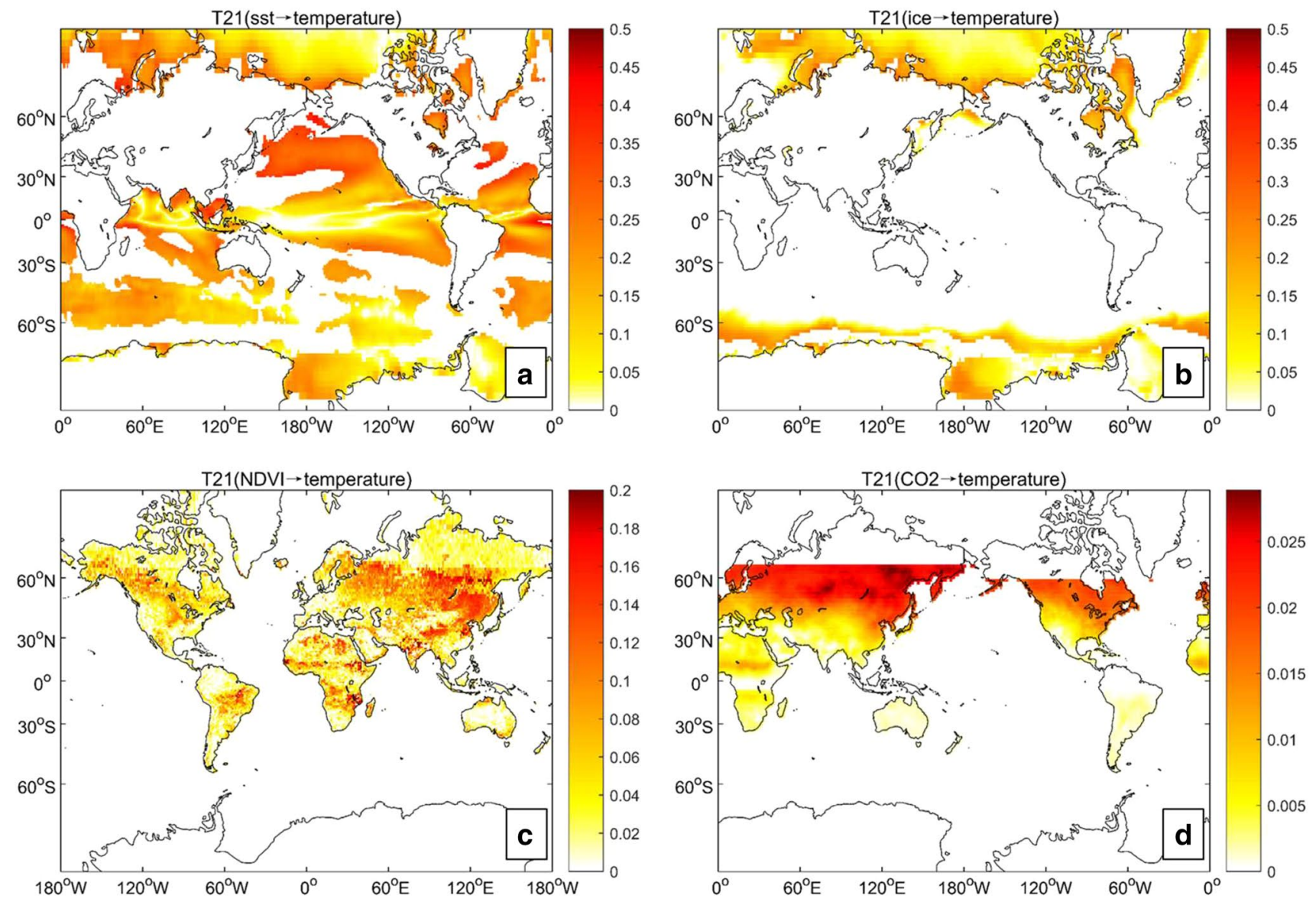

Fig. 1 Spatial distribution of information flow from different forcings to the global average temperature. a Sea temperature, b Sea ice, $\mathbf{c}$ Land cover NDVI index, $\mathbf{d}$ carbon dioxide (filling; unit: nats/month). All shading areas exceed $95 \%$ significance level 


\subsection{Model introduction and experiment design}

The CAM4.0 model used in the study is Version 4.0 of the Community Atmosphere Model (CAM) developed primarily at the National Center for Atmospheric Research (NCAR) (Neale et al. 2010; Gent et al. 2011). CAM4.0 is the latest in a series of global atmosphere models and contains same notable improvements. In addition, CAM 4.0 also includes the Land Surface Module CLM4.0, which provides atmospheric conditions with land boundary conditions and lower boundary conditions such as energy, momentum and water vapor exchange between land and air (Oleson et al. 2010). It has three optional power cores: the Euler spectrum core, the finite volume core and the half Lagrangian core, where the Euler spectrum include T85, T63, T42, T31 and other resolutions. The horizontal resolution of the model used in this paper is T85 $\left(128 \times 256\right.$, about $\left.1.5^{\circ}\right)$. The $\sigma$-p hybrid coordinates are taken in the vertical direction. The $\sigma$ coordinates are used in the near ground layer. The $\sigma$-p transition coordinates are used in the middle, and the upper layer is the pure $\mathrm{p}$ coordinate, covering 26 layers. The deep convection process is processed using a parametric scheme developed by Zhang and McFarlane (1995) and corrected by the increased flow transport of Richter and Rasch (2008). Compared with CAM3.0, the default power core of CAM4.0 has been changed from the original spectral core to a finite volume core. CAM4.0 has also significantly improved on deep convection scheme, Arctic cloud simulation, radiated interface and computational scalability. It also improves simulation capabilities for ENSO (Neale et al. 2008).

The time scales of the data currently available for download such as temperature and precipitation is generally from 1948 to present, we use the data from 1948 to 2017. The data of these 70 years are divided into the former 35 years (1948-1982) and the latter 35 years (1983-2017), and calculate the average climatic states of the two. The difference between these climate states as the observation is compared with the simulation results. Therefore, in the design of the experiments, the control experiment uses the 2000 (the intermediate year from 1983 to 2017) condition as the forced field, and the contrast experiments use the 1965 (the intermediate year from 1948 to 1982) condition as the forced field. Due to the lack of land cover data, the land cover situation before and after the industrial revolution is used as the forced field for the land cover contrast experiment. Six 30-year simulations are carried out from year 2000 to 2029 to explore the possible impacts of different forcings on climate. The model was run with $\mathrm{T} 85$ horizontal resolution and 26 levels in the vertical direction. Table 1 is the experiment design.

Figure 2 shows the difference between the forced field of the control and contrast experiments. For the LCC, compared with the CTRL, the forcing field shows a decrease in broad-leaved forest and grassland, and the farmland area increases significantly (Fig. 2a-c). The sea ice shows a consistent decrease in the north and south poles, with a small increase in the area around $60^{\circ}$ (Fig. 2d-f). The SST mostly rises, but in the mid-latitude (Aleutian area) decreases. In the eastern equatorial Pacific, SST decreases in summer and increases in winter (Fig. 2g-i). Based on the different changes in these forced fields, we set six experiments (one control experiment, five contrast experiments) to research the climate effects of different forcings.

\section{Comparison analysis of observation and simulation results}

\subsection{Global temperature change}

The areas where the sign of simulation results are consistent with the observation are shadowed. It can be seen from the figure that most of the simulation results are consistent with the reality (Fig. 3). In the AC (Fig. 3d-f), the annual average temperature has the overall warming trend about $0.8 \mathrm{~K}$, which is more obvious in the high latitudes. In winter, observations and simulations show overall warming, but there is cooling in some parts of Europe and western North America. The change of $\mathrm{CO}_{2}$ leads to a warming trend in Asia. In Europe, there is a cooling trend in winter, which is consistent with the observation. In North America, there is a trend of summer warming and winter cooling consistent with other contrast experiments (Fig. $3 g-i$ ). The results of LCC (Fig. 3j-1) show the temperature rising in summer, but
Table 1 Experiment design

\begin{tabular}{ll}
\hline Experiment & Description of the forcing fields \\
\hline CTRL & All forcings $\left(\mathrm{CO}_{2}\right.$, land cover, sea ice, SST) are fixed to the year 2000 \\
AC & All forcings $\left(\mathrm{CO}_{2}\right.$, land cover, sea ice, $\left.\mathrm{SST}\right)$ are fixed to the year 1965 \\
CO2C & Same as CTRL but the $\mathrm{CO}_{2}$ concentration decreases from 368.7 (in \\
& 2000) to 319.7 ppm (in 1965) \\
LCC & Same as CTRL but the land cover type is fixed to the year 1965 \\
SIC & Same as CTRL but the sea ice is fixed to the year 1965 \\
SSTC & Same as CTRL but the SST is fixed to the year 1965 \\
\hline
\end{tabular}



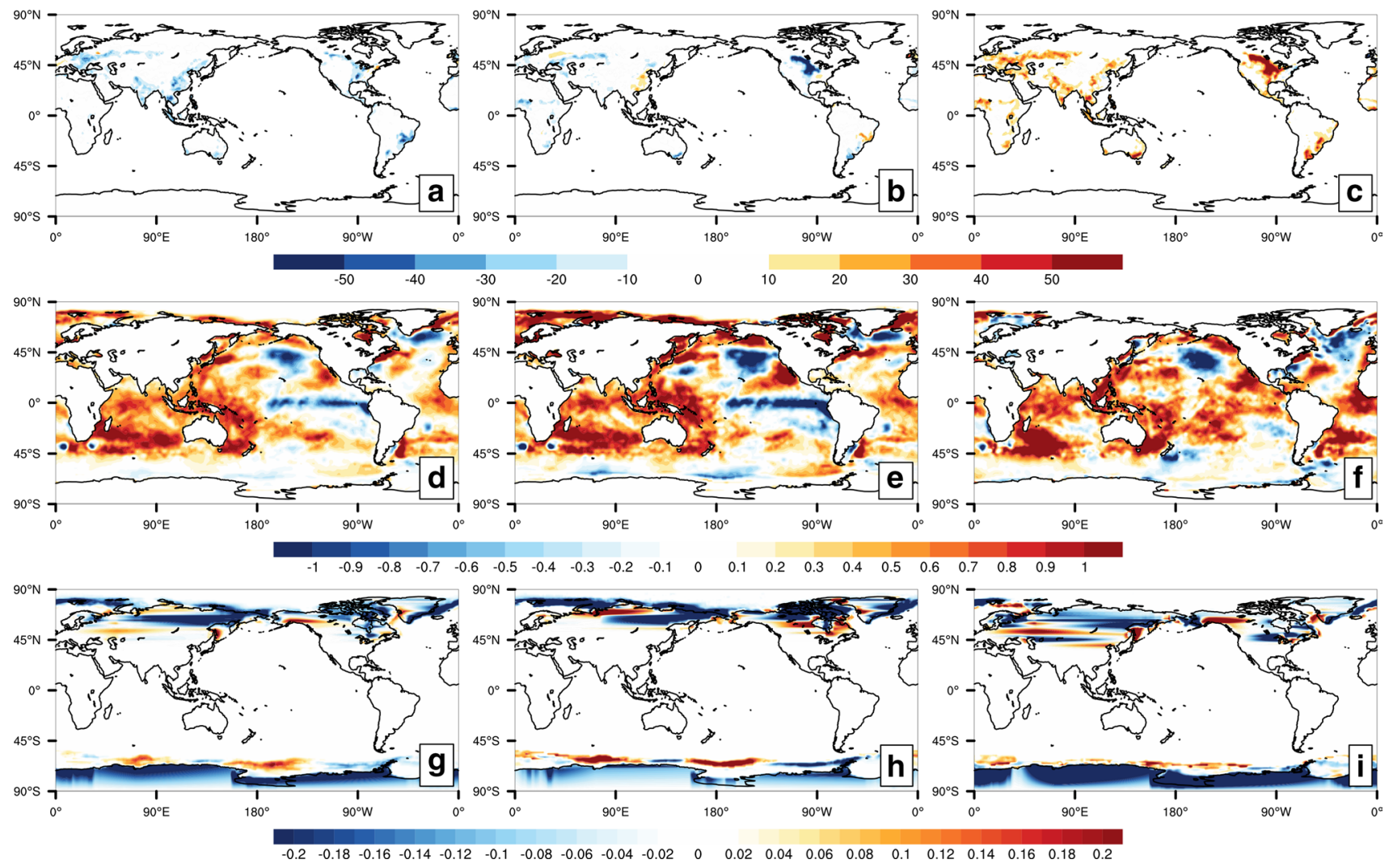

Fig. 2 Change in forced field between control and contrast experiments. a Forest cover (temperate evergreen coniferous forest, frigid evergreen coniferous forest, frigid deciduous coniferous forest, tropical evergreen broad-leaved forest, temperate evergreen Leaf forest, tropical deciduous broad-leaved forest, temperate deciduous broadleaved forest, deciduous broad-leaved forest, evergreen broad-leaved shrub forest, temperate deciduous shrub forest, deciduous shrub for-

in the winter, North Asia and the North America show the cooling trend. The change of sea ice has the greatest impact on the warming of high latitudes. In winter, there are the warming trend in Asia and cooling trend in Europe, which are consistent with observations (Fig. 3m-o). The results of SSTC show that the eastern part of Asia has a warming trend both in winter and in summer, while in Europe it shows a cooling trend. It is also worth noting that the warming trend of the simulation results is not obvious if only one forcing changes, but when all forcings change, the temperature increases obviously, which is consistent with the observation. What's more, we found the linear superposition of the contrast experiments results (Fig. 3s-u) is not consistent with the results of AC (Fig. 3d-f), which means the nonlinear feedback plays an important role and there is an interaction between different forcings. Therefore, we analysis the causation between $\mathrm{CO}_{2}$ and other forcings. It can be seen that $\mathrm{CO}_{2}$ has a significant effect on the change of sea surface sea ice and land cover (Fig. 4a-c). However, the reverse causality (other forcings to $\mathrm{CO}_{2}$ ) is not obvious est in cold zone), b grassland cover (polar C3 grassland, non-Polar C3 grassland, C4 grassland), $\mathbf{c}$ farmland cover (grain, wheat) (filling, unit: percent), $\mathbf{d}-\mathbf{f}$ sea ice cover (d annual average, e summer average, f winter average; filling, unit: deg_C), $\mathbf{g}$-i sea surface temperature (g annual average, $\mathbf{h}$ summer average, $\mathbf{i}$ winter average; filling, unit: fraction)

(Fig. 4d-f). This implies there is a "capacitor effect" in the change of land cover, SST and sea ice, which stores and indirectly releases the climate impact of carbon dioxide. Therefore, changes in a single forcing can't cause significant climate effects, and the evident climatic warming trend occurs after all forcings change. Previous studies (Sutton 2000; Robinson 2003; Deser et al. 2004) have also shown that the response of the atmosphere to total forcing is not equal to the sum of the responses of the various parts, which is "additional nonlinearity".

Tables 2 and 3 show the coincidence rate of sign (positive or negative) between each experiment and observation, and the rate in each region in $\mathrm{AC}$. We use this to represent the proportion of areas where the sign of simulation results are consistent with the observation. After changing all forcings, the annual average coincidence rate is high to $80 \%$ or more.

Based on the above, the following conclusions are obtained: From 1979 to 2017, the global temperature showed an overall warming trend. In the simulation, by changing the $\mathrm{CO}_{2}$, land cover, sea ice and SST, the temperature rises, 


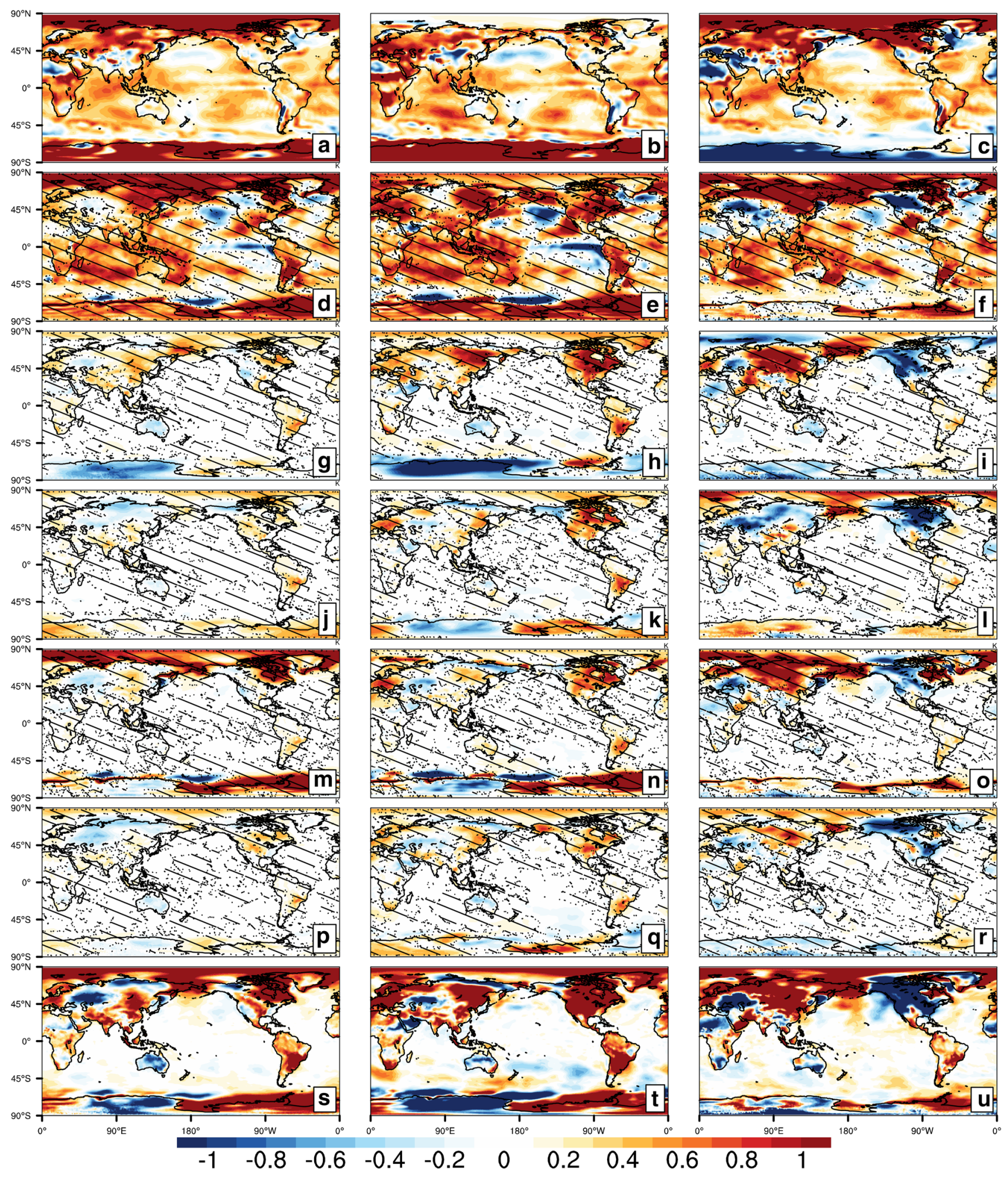

Fig. $32 \mathrm{~m}$ temperature. Difference between a-c 1983-2017 and 1948-1982. Difference between control and contrast experiments. $\mathbf{d}-\mathbf{f}$ AC, $\mathbf{g}-\mathbf{i}$ CO2C, $\mathbf{j}-\mathbf{l}$ LCC, $\mathbf{m}-\mathbf{0}$ SIC, $\mathbf{p}-\mathbf{r}$ SSTC, $\mathbf{s}-\mathbf{u}$ the sum of all contrast experiments (filling, unit: $\mathrm{K}$; the black slash area is the part that the sign of actual trend is same as the simulation result; left column: annual average, middle column: summer average, right column: winter average) 

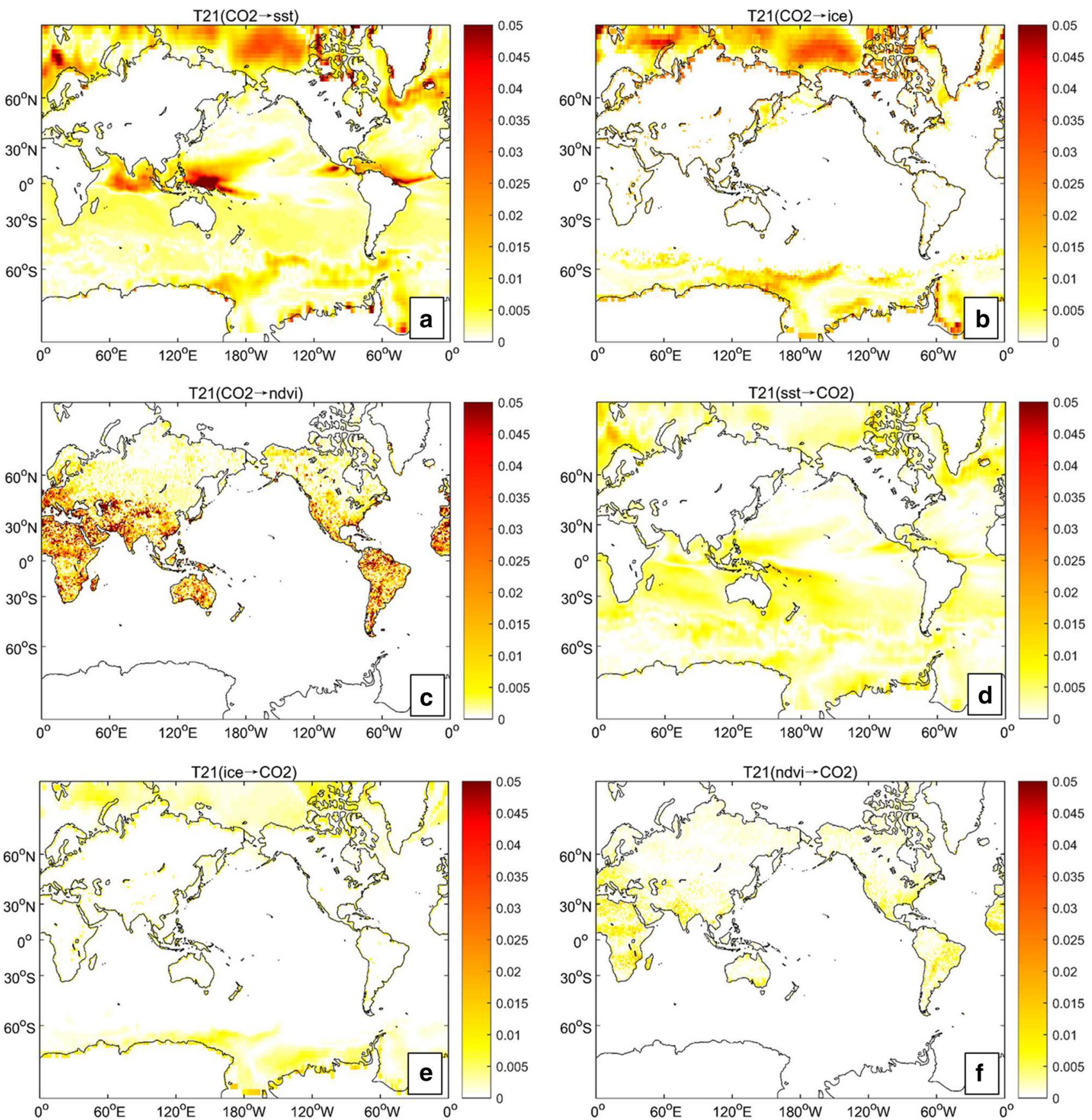

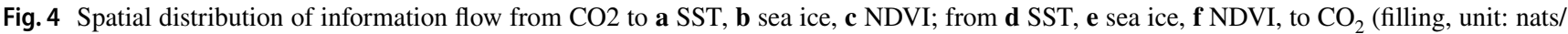
month). All shading areas exceed $95 \%$ significance level

Table 2 Sign consistency rate between simulation and observation

\begin{tabular}{llll}
\hline Sign consistency rate & Annual (\%) & Summer (\%) & Winter (\%) \\
\hline AC (all change) & 81.0 & 79.3 & 67.2 \\
CO2C ( $\mathrm{CO}_{2}$ changes) & 63.1 & 56.4 & 56.8 \\
LCC (land cover changes) & 62.9 & 56.7 & 53.1 \\
SIC (sea ice changes) & 57.1 & 55.1 & 57.8 \\
SSTC (SST changes) & 66.0 & 60.2 & 57.1 \\
\hline
\end{tabular}

which is consistent with the observations, indicating that the changes of these forcings are parts of the cause of the global warming. For Asia's warming, carbon dioxide and sea ice have contributed the most, while Europe's cooling trend in winter is affected by all these forcings. For North America, almost all the contract experiments show an unstable trend of warming in summer and cooling in winter. By analyzing the causality between the carbon dioxide and other forcings, 
Table 3 Sign consistency rate between AC and observation

\begin{tabular}{llll}
\hline Sign consistency rate & Annual (\%) & Summer (\%) & Winter $(\%)$ \\
\hline Eurasia & 81.5 & 83.2 & 72.4 \\
North America & 82.3 & 88.2 & 63.4 \\
South America & 89.6 & 75.5 & 93.4 \\
Africa & 71.1 & 79.7 & 78.4 \\
Oceania & 79.8 & 68.3 & 57.8 \\
Antarctica & 87.5 & 90.4 & 25.5 \\
Pacific & 75.9 & 74.3 & 64.2 \\
Atlantic & 78.3 & 82.3 & 68.3 \\
Indian Ocean & 68.7 & 63.2 & 58.5 \\
Arctic & 92.7 & 79.1 & 89.7 \\
\hline
\end{tabular}

we find that there is a "capacitor effect" in the change of land cover, SST and sea ice, which stores and indirectly releases the climate impact of carbon dioxide.

Solar radiation is the main source of energy for the Earth, and the amount of net solar radiation absorbed directly affects the air temperature. Figure 5 shows the net solar radiation variation in the simulation. It can be seen from the figure that the increase of $\mathrm{CO}_{2}$ mainly leads to the increase of net short-wave radiation in Asia and Europe in winter and the decrease in North America (Fig. 5f). Changes in land cover cause a reduction in radiation both in winter and in summer. The reason for this is that the decrease of forests and the significant increase in farmland increase the surface albedo. In the SIC, high latitude region has the most obvious changes, which is consistent with the area where the temperature changes obviously. Due to the melting of sea ice,

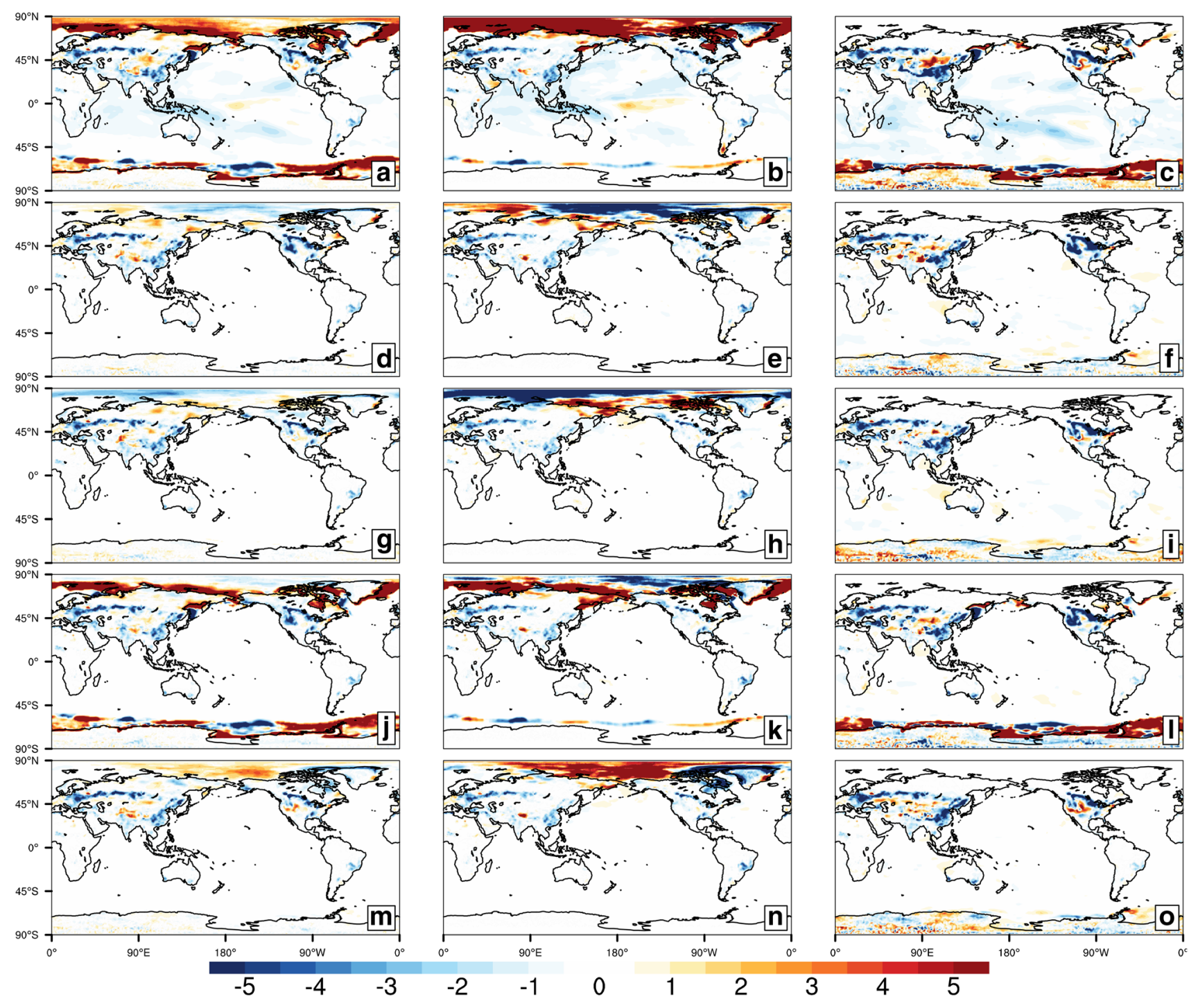

Fig. 5 The difference of surface net solar radiation between control and contrast experiments. a-c AC, $\mathbf{d}-\mathbf{f} \mathrm{CO}_{2} \mathrm{C}, \mathbf{g}-\mathbf{i}$ LCC, $\mathbf{j}-\mathbf{l}$ SIC, $\mathbf{m}-\mathbf{0}$ SSTC (filling, unit: $\mathrm{W} / \mathrm{m}^{2}$; left column: annual average, middle column: summer average, right column: winter average) 
areas covered by sea ice reduce and then the albedo reduces in these areas. Therefore, the net short-wave radiation in the Arctic region increases significantly in summer, while the Antarctic region increases in winter. The warming of SST leads to an increase in net short-wave radiation in central North America in winter, while in Asia, the central region increases and the south decreases, and the European shows a decrease trend both in winter and in summer. It can be also observed that in AC, there is a slight decrease in the summer hemisphere. The radiation changes of each experiment are different from the temperature changes analyzed above, which indicates that the air temperature is not only directly affected by radiation, but also affected by the atmospheric dynamic process, which will be analyzed below. It is also worth noting that the results of each experiment show that in the summer, the net short-wave radiation in the Arctic Ocean increases, while in the winter (the summer in the southern hemisphere), although the radiation in the Antarctic also increases, the range and intensity are smaller compared to that of the Arctic. This is consistent with the observation that the decreasing trend of sea ice in the Arctic is more obvious than the Antarctic (Cavalieri et al. 1997, Comiso and Nishio 2008).

In Fig. 6, the circles are the reference points of PacificNorth American Pattern (PNA), which are south of $30^{\circ} \mathrm{N}$ (centered on the island of Hawaii) and north of $40^{\circ} \mathrm{N}$ (centered on the south of the Aleutian Islands). The triangles are reference points of the North Atlantic Oscillation (NAO), which are the Icelandic low pressure and the Azores high pressure. It can be seen in the observation and simulation results, the PNA positive phase and the NAO positive phase are more obvious in winter. The results of almost all contrast experiments are positive phase of PNA in winter, showing an obvious enhancement in Aleutian low, and the potential trend of the Pacific (high potential in south and low in north) is obvious. In this situation, the intensity of the mid-ocean ridge in the North Pacific Ocean weakens, and its position moves eastward, which directly leads to an increase in the amplitude of the high-pressure ridge in western North America. The effect of upper and lower courses of the Rossby wave in westerlies are fed back to the large trough in North America, so the bottom of the trough extends southward and the strength is enhanced. It is easier for the polar vortex to dive into the southeastern areas of North America, and lead to cooling (Namias 1969). Whereas in the observation, this feedback is not as strong as expected, and there is no obvious low pressure in the southeastern part of North America. As the upstream, in the western part of North America, the temperature is higher because the ridge is stronger than normal. Therefore, it can be seen a warming trend in North America and the southern region has a slight cooling. In terms of NAO analysis, the results of $\mathrm{CO} 2 \mathrm{C}$ and SIC show the negative phase of NAO. In this case, the westerly wind over the North Pacific weakens, and the north jet and south jet move southward, and the strength is weakened. The westerly circulation is mainly meridional, which is beneficial to the exchange of heat, vorticity and angular momentum between high and low latitudes. Therefore, the bottom of the North American trough is southward, the trough line is westward, and the Mid-Atlantic Ridge is strong. In winter, the activity of cold wave and cold air is obvious in the southeastern North America and most of Europe, so the Europe has a cooling trend (Hurrell 1996; Wang et al. 2010). In the summer, the AO positive phase appears in the high latitude area in all contrast experiments. In this situation, the Arctic polar vortex is distributed around the polar, and the cold source are concentrated in the polar. The potential in polar regions is low, and the potential in the middle and high latitudes is high. Hence, it is conducive to cold air accumulating in polar regions, and most areas of the northern hemisphere is warmer (Thompson and Wallace 2000). Therefore, it can be seen that in the summer of each experiments, the most regions in the mid-high latitudes in the northern hemisphere have a warming trend. It can be concluded that the increase of $\mathrm{CO}_{2}$ and SST, the change of land cover, and the sea ice melting cause the $\mathrm{AO}$ positive phase distribution, and the temperature in most parts of the northern hemisphere warms. The cold winter in Europe is mainly due to the increase of $\mathrm{CO}_{2}$ and the melting of sea ice, leading to the appearance of the NAO negative phase and bringing cold winter.

\subsection{The precipitation situation in East Asia}

Under the background of global warming, precipitation events are also showing an extreme trend, and precipitation distribution has a great influence on people's life and economic development. The precipitation situation around the world is complicated. Due to the limitations of coverage, only the precipitation in East Asia is selected for analysis. The monsoon region in East Asia is vulnerable to meteorological disasters such as drought, heavy rain and flood, and China is one of the regions which is most likely to be affected by meteorological disasters and causing severe damage. The research of precipitation anomalies in East Asia has great significance in the prevention of drought or flood disasters in the monsoon region and the development of social economy.

It can see from Fig. 7 that in the observation, the annual precipitation mainly has an increasing trend, but decreases around $30^{\circ} \mathrm{N}$. The western China (Xinjiang, Tibet) and the southern area and eastern coastal areas show an increase in precipitation, while the precipitation in the southwest (such as Yunnan), central and Taiwanese areas decreases. Although the precipitation variation in the simulation is larger than the observation, the results of the $\mathrm{AC}$ and $\mathrm{CO} 2 \mathrm{C}$ 
Fig. 6500 hpa height field. Difference between a-c 1983-2017 and 1948-1982. Difference between control and contrast experiments. d-f AC, $\mathbf{g}-\mathbf{i} \mathrm{CO} 2 \mathrm{C}, \mathbf{j}-\mathbf{l} \mathrm{LCC}, \mathbf{m}-\mathbf{o}$ SIC, p-r SSTC (filling, unit: dagpm; the circles are PNA reference points, the triangles are the NAO reference points; left column: annual average, middle column: summer average, right column: winter average)
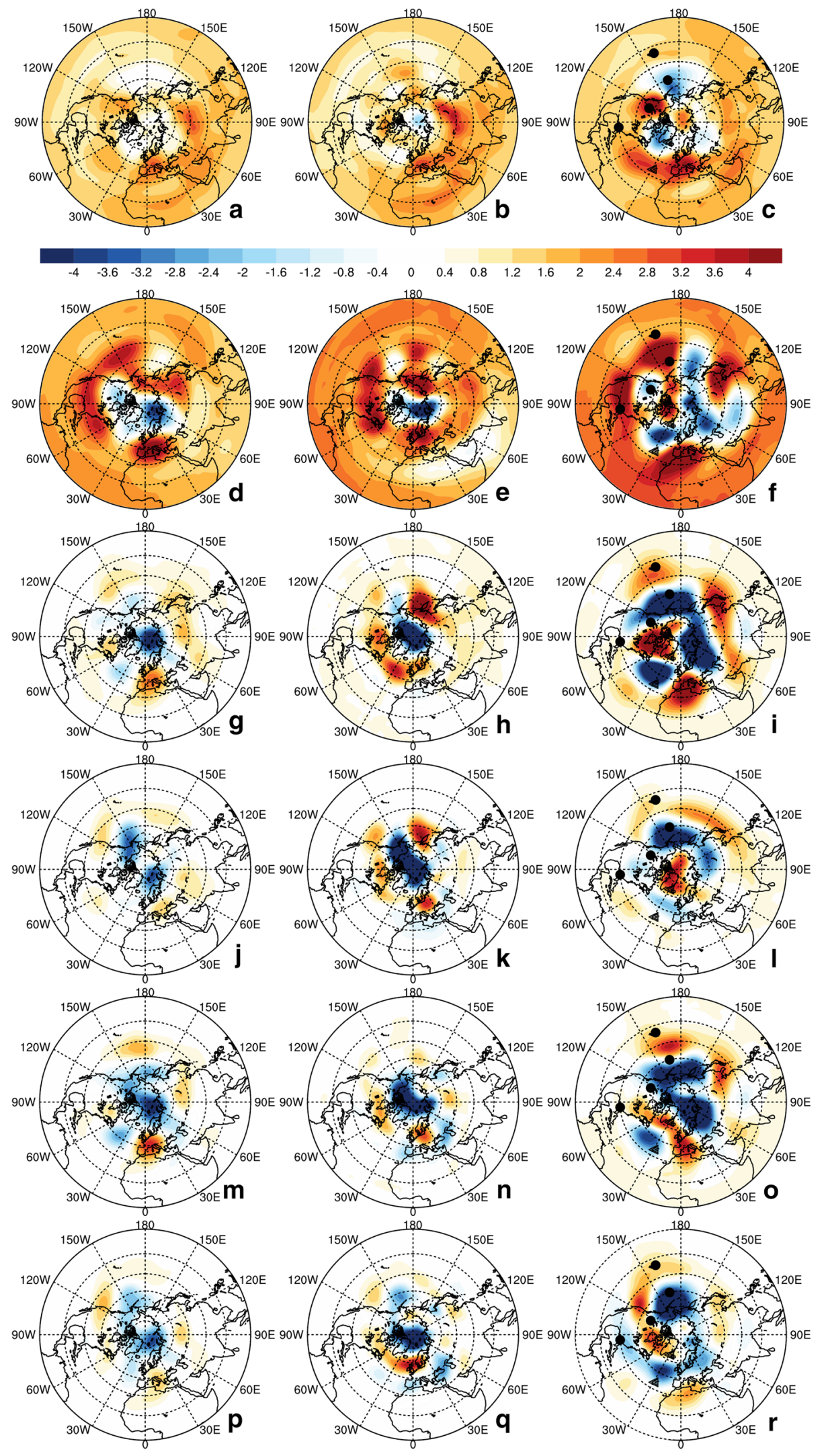

$\begin{array}{lllllllllllllllllllll}-2 & -1.8 & -1.6 & -1.4 & -1.2 & -1 & -0.8 & -0.6 & -0.4 & -0.2 & 0 & 0.2 & 0.4 & 0.6 & 0.8 & 1 & 1.2 & 1.4 & 1.6 & 1.8 & 2\end{array}$ 

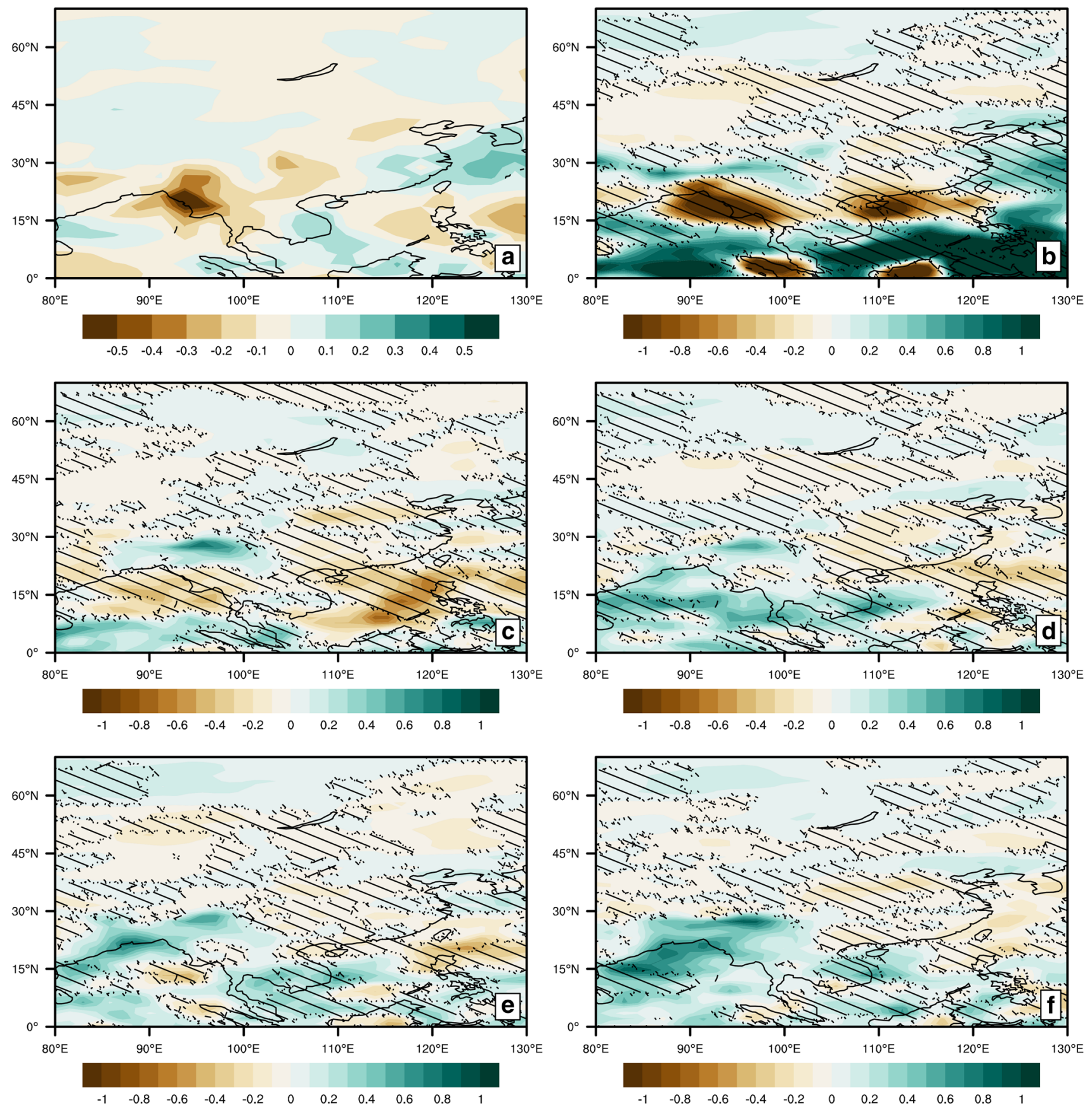

Fig. 7 The annual average total precipitation. Difference between a 1983-2017 and 1948-1982. Difference between control and contrast experiments. b AC, c CO2C, d LCC, e SIC, f SSTC (filling, unit: $\mathrm{mm} /$ day; shadow is the part that the actual trend is same as the simulation result)

are almost the same as the actual trend (Fig. $7 \mathrm{~b}, \mathrm{c})$. Changes in land cover and sea ice will bring about the similar but not obvious trends (Fig. 7d, e). In the SSTC, the change in sea temperature brings about an increase in precipitation, and there is a slight decrease in the central region. In summary, the precipitation mainly increases in East Asia, but shows a decreasing tendency around $30^{\circ} \mathrm{N}$ due to the carbon dioxide change.
In simulation, the precipitable water in almost all regions of East Asia shows an increasing trend, and only in the southwestern areas, there is a decreasing trend, which is also reflected in observation. From the wind field, we can see the wind from ocean to land enhances (Fig. 8), and a large amount of water is brought from the ocean to the land, so the moisture content in the atmosphere and the amount of precipitable water in East Asia is increased. What's more, the 

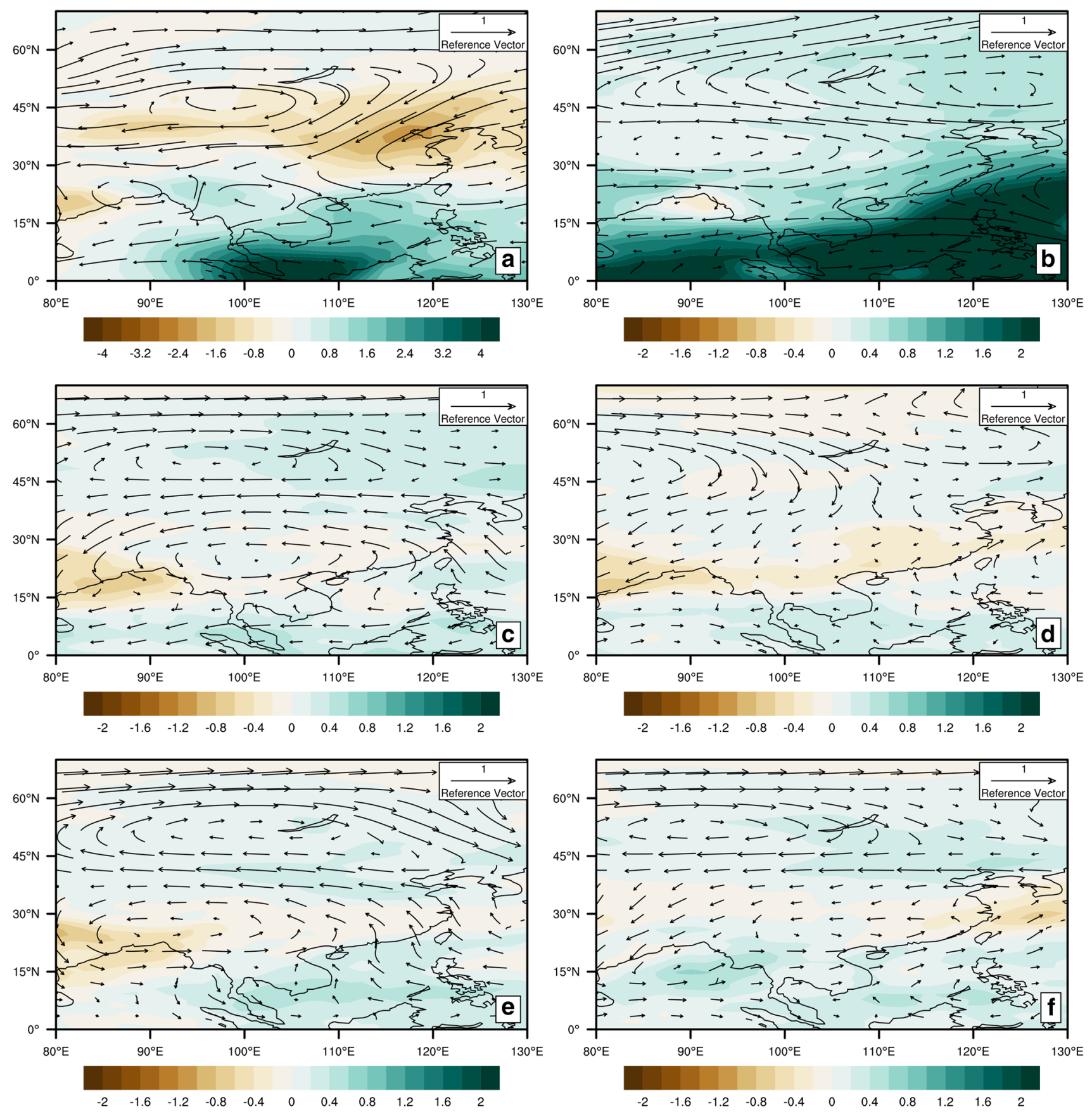

Fig. 8 The annual average precipitable water and wind in $500 \mathrm{hpa}$. Difference between a 1983-2017 and 1948-1982. Difference between control and contrast experiments. b AC, c CO2C, d LCC, e SIC, f SSTC (precipitable water: filling, unit: $\mathrm{kg} / \mathrm{m}^{2}$; wind: vector arrow, unit: $\mathrm{m} / \mathrm{s}$ )

wind field changes are mainly zonal, and the change is small in north south horizontal direction, so the main role of wind change is reflected in the east-west moisture transport. The results of almost all contrast experiments show that the wind from the ocean to the land enhances in East Asia, which will bring more water vapor from the sea surface to East Asia, increasing the water content in the atmosphere. Therefore, the precipitation has an increasing trend overall in East Asia.
Although the precipitable water shows an increasing trend overall in almost all the simulation results, the actual precipitation changes are not consistent with the precipitable water and are more complex due to the change of the vertical wind. In some areas, even if the moisture in the atmosphere increases, the precipitation cannot be generated due to the lack of dynamic conditions of rainfall. The change of all forcings will bring obvious changes in the 

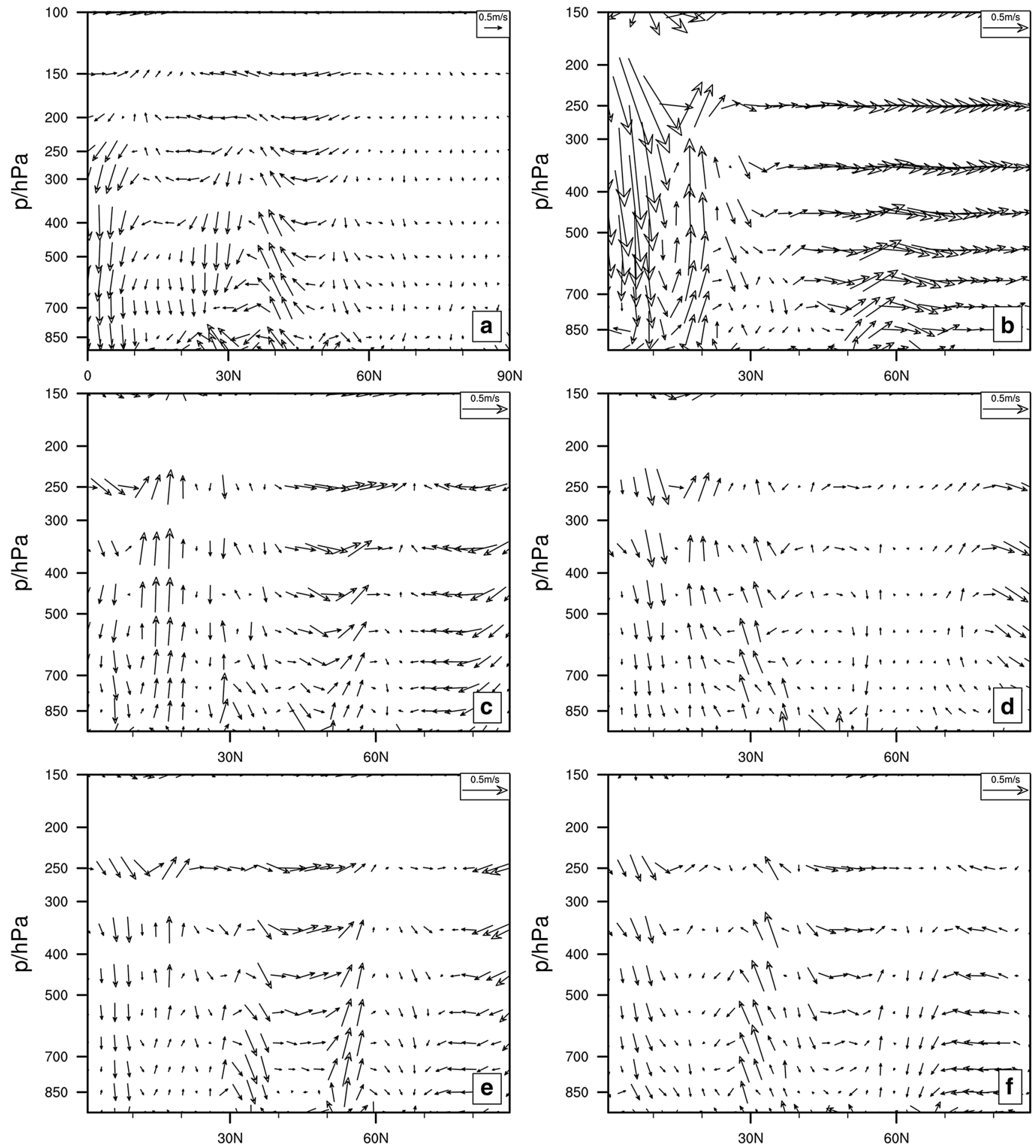

Fig. 9 The annual average East Asian circulation situation profile. Difference between a 1983-2017 and 1948-1982. Difference between control and contrast experiments. b AC, c CO2C, d LCC, e SIC, f SSTC (vector arrow; unit: $0.5 \mathrm{~m} / \mathrm{s}$ )

circulation, including a strong sinking airflow in south of $10^{\circ} \mathrm{N}$ and around $30^{\circ} \mathrm{N}$ (Fig. 9b). Compared with the actual situation, the general trend is the same, dominated by downdraft. However, the simulation results of the AC have a significant upward airflow between $10^{\circ} \mathrm{N}$ and $20^{\circ} \mathrm{N}$, which is not obvious in the observation, so the simulation results show more precipitation than observation in these regions (Fig. 9a, b). In other contrast experiments, the intensity of the change in circulation is not as strong as that of the $\mathrm{AC}$, so the amount of precipitation change is less. In addition, the 

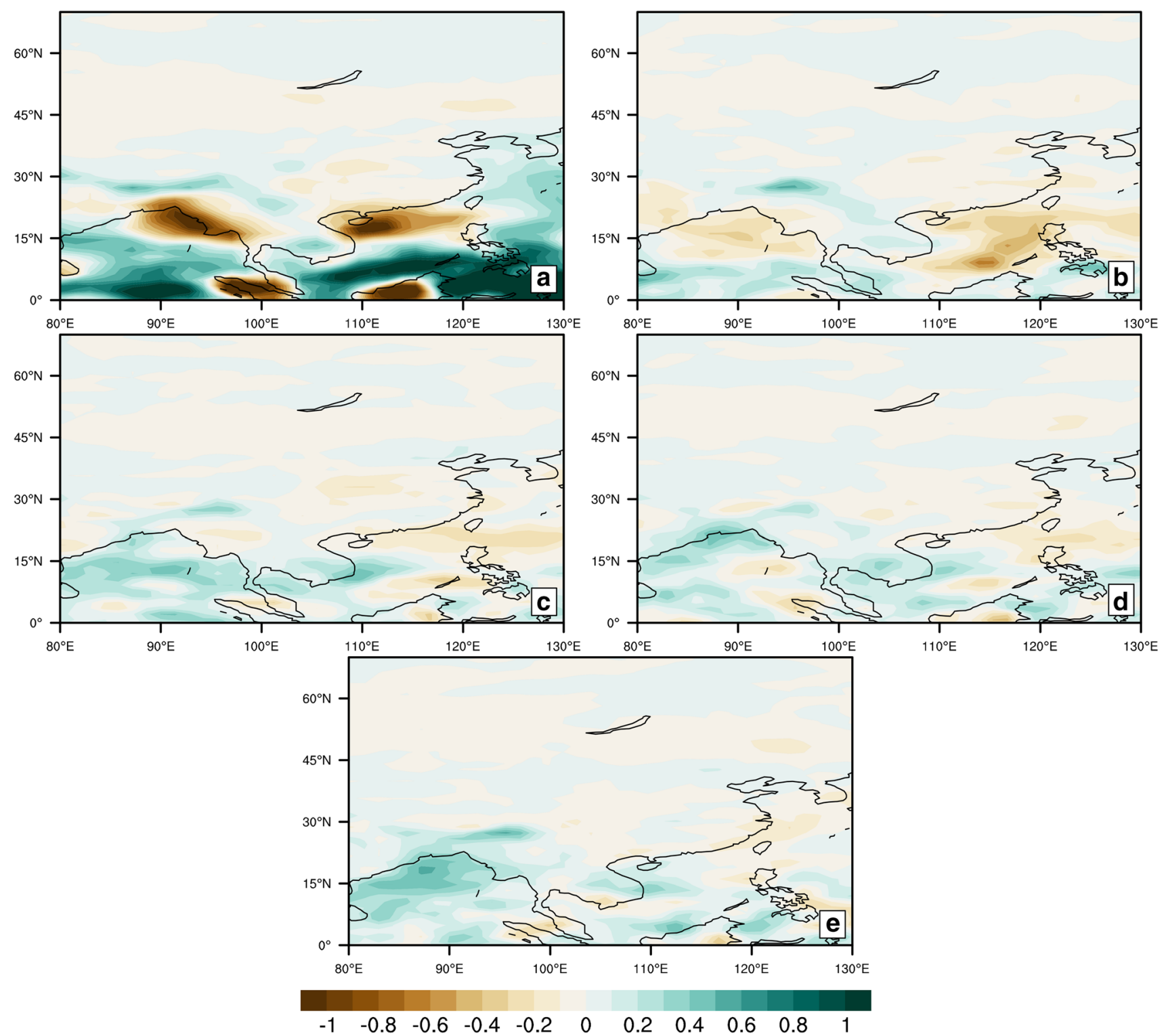

Fig. 10 The annual average convective precipitation. Difference between control and contrast experiments. a AC, b CO2C, c LCC, d SIC, e SSTC (filling; unit: $\mathrm{mm} /$ day)

simulation result of $\mathrm{CO} 2 \mathrm{C}$ shows similar changes with $\mathrm{AC}$, so the carbon dioxide is the main causes of the downdraft in all forcings (Fig. 9c). In the simulation results, the total precipitation consists of two parts: large-scale precipitation and convective precipitation. Figure 10 shows the variation of convective precipitation in each experiment. Due to the influence of the downdraft flow in south of $30^{\circ} \mathrm{N}$, the test results of the $\mathrm{AC}$ and $\mathrm{CO} 2 \mathrm{C}$ have a significant decrease trend in the convective precipitation. Therefore, the total precipitation decreases in these areas.

\section{Summary and discussion}

In this study, firstly, using the Liang-Kleeman information flow method, we established that there is a causal relationship from carbon dioxide, land cover, sea ice, SST to air temperature (Fig. 1). By taking advantage of the quantitative nature of this method, spatial distributions of the impacts are revealed, and hence several key regions are identified: the sea ice edge (sea ice); Eurasia and North America (land cover and $\mathrm{CO}_{2}$ ). There is a more significant causal relationship in these regions. However, the climate change in observations is affected by all forcings, and the individual climate effects of each forcing is difficult to analyzed. The 
observations alone are not enough to tell the details about how the climate reacts. What's more, we identify the several key regions by using the Liang-Kleeman information flow method. Hence, the CAM4.0 model is used to verify whether there are more pronounced and attractive climate effects in these key areas. Moreover, the model verification can help us analysis how the climate changes in these areas. The forced field in 2000 is used as the control experiment. As the contrast experiments, the carbon dioxide, land cover, sea ice, SST and all of them in the forced field are changed to their situation in 1965 (Table 1).

Based on the simulation results of temperature, the climate effects caused by multiple forcings are discussed. When all forcings change, the change of temperature is very similar to the observation, the proportion of areas where the sign of simulation results are consistent with the observation is as high as $80 \%$ or more. The annual average temperature has a warming trend overall, but the trend is not obvious if only one forcing changes. The linear superposition of the contrast experiments results is not consistent with the results of $\mathrm{AC}$, which means the nonlinear feedback plays an important role, and there is an interaction between different forcings. Therefore, the causation between $\mathrm{CO}_{2}$ and other forcings is analyzed. The results indicate that $\mathrm{CO}_{2}$ has a significant effect on the change of sea surface sea ice and land cover, but the reverse causality (other forcings to $\mathrm{CO} 2$ ) is not strong (Fig. 4). This illustrates there is a "capacitor effect" in the change of land cover, SST and sea ice, which stores and indirectly releases the climate impact of carbon dioxide. The change of different forings influence air temperature through radiation and atmospheric dynamic adjustment. The increase of $\mathrm{CO}_{2}$ leads to the increase of net short-wave radiation in parts of Asia in winter, and the decrease in North America. Changes in land cover characterized by a decrease in forests and a significant increase in farmland have led to an increase in surface albedo, leading to a reduction in radiation. The decrease of sea ice covered area reduce the albedo, so the net short-wave radiation increases in high latitudes. In the simulation of SST changes, the radiation changes are complicated. It increases in central North America during the winter, while in Asia, the central region increases and the south decreases. The Europe showed a decrease trend both in winter and in summer. It is not hard to see that the radiation change is not completely consistent with the air temperature change, so the analysis of the atmosphere dynamic adjustment is important. The change of $\mathrm{CO}_{2}$, land cover, sea ice and SST will bring about the positive PNA phase, which makes it easier for most parts of North America to influenced by polar vortices. Therefore, the cooling trend in North America is stronger and wider. The negative phase of NAO caused by the change of $\mathrm{CO}_{2}$ and sea ice is the reason why cold winter appears in Europe. In summer, all forcings lead to the AO positive phase, causing the temperature in most parts of the northern hemisphere warmer.

The air temperature changes caused by different forcings in different regions is various. Even under the same forcing, the effects of radiation changes and atmospheric dynamics on temperature may be reversed. Therefore, temperature changes in various regions have strong uncertainties. Overall, Europe and North America have a strong cooling trend in winter, and the latest news reports show that the two regions did have an extremely cold climate this year (2019). Whether the occurrence of extreme cold weather in winter is related to the radiation and atmospheric dynamic processes caused by the forcings analyzed in this paper requires further research.

In addition to temperature, another most important meteorological factor is precipitation. This paper mainly analyzes the precipitation in East Asian monsoon region where meteorological disasters are frequent and closely related to China's production and life. Precipitation is affected by the change of moisture content (directly affects the precipitable water) and dynamic processes. The changes in all forcings will increase Sea-Land breeze in East Asia, resulting in changes in precipitation that are consistent with observations. The wind blowing from the ocean to the land is enhanced, bringing more water vapor, so the precipitable water increased apparently (Fig. 8). In a word, the precipitation increases in most parts of East Asia, only in the southwest it decreases. Therefore, the causes of precipitation reduction in these areas are analyzed. In the simulation results of the $\mathrm{AC}$ and $\mathrm{CO} 2 \mathrm{C}$, due to the obvious sinking airflow in some areas (south of $30^{\circ} \mathrm{N}$ ), there is a lack of precipitation dynamic conditions and thus the precipitation reduces.

The previous numerical studies (Potter and Cess 1984; Jacobson et al. 2007; Lim et al. 2014) have shown that not only these forcings discussed above, but also other forcings, such as aerosol, have great influence on climate. On the other hand, the impact of land use change in different regions is also different. For example, in Southeast Asia, deforestation and agricultural development influence the ozone and aerosol concentrations, and affect long-wave radiation (Harper et al. 2016). In arid regions, land cover change has a significant influence on water circulation, and then affects the precipitation (Bagley et al. 2014; Chen et al. 2016). The role of aerosols is not considered in this paper, and there is no subregional discussion when changing land cover. What's more, the data sources also influence the simulation results. In addition, as mentioned above, the variation of Arctic sea ice is different from that of Antarctic (Comiso and Nishio 2008), so are the climate effects different? These will be carried out in future work. 
Acknowledgements All the authors contributed equally to this work. The authors thank the anonymous reviewers for their valuable comments and suggestions. This work has benefited from discussions with William Perrie of BIO. This work was supported by the National Key Program for Developing Basic Science (Grant Nos. 2016YFA0600303 \& 2018YFC1505900), the National Natural Science Foundation of China (Grant Nos. 41330420 \& 41621005 \& 41675064 \& 41675067 \& 41875086), the Jiangsu Province Science Foundation (Grant No. SBK2015020577). The authors are thankful for the support of the Jiangsu Provincial Innovation Center for Climate Change and Fundamental Research Funds for the Central University. This work was jointly supported by the Joint Open Project of KLME and CIC-FEMD (Grant KLME201902). The NCEP/NCAR reanalysis data used in this study was obtained from https://www.esrl.noaa.gov/psd/data/gridded/ data.ncep.reanalysis.html.The NOAA OISST data used in this study was obtained from https://www.esrl.noaa.gov/psd/data/gridded/data. noaa.oisst.v2.html. The NDVI data was obtained from ECOCAST (https://ecocast.arc.nasa.gov/data/pub/gimms/3g.v1/). The $\mathrm{CO}_{2}$ data used in this study was obtained from the fusion of three satellite data (Crisp 2004; Reuter et al. 2011; Crisp et al. 2012; Belikov et al. 2014), includes http://www.esa-ghg-cci.org/sites/default/files/documents/publi c/documents/GHG-CCI_DATA.html; https://oco2.gesdisc.eosdis.nasa. gov/data/s4pa/OCO2_DATA/OCO2_L2_Lite_FP.7r/) The monthly $\mathrm{CO}_{2}$ data was obtained from https://www.co2.earth/monthly-co2. The numerical calculations in this paper have been done on the Blade cluster system in the High Performance Computing \& Massive Data Center (HPC\&MDC) of School of Atmospheric Science, Nanjing University.

Open Access This article is distributed under the terms of the Creative Commons Attribution 4.0 International License (http://creativeco mmons.org/licenses/by/4.0/), which permits unrestricted use, distribution, and reproduction in any medium, provided you give appropriate credit to the original author(s) and the source, provide a link to the Creative Commons license, and indicate if changes were made.

\section{References}

Alexander MA, Bladé I, Newman M et al (2001) The atmospheric bridge: the influence of ENSO teleconnections on air-sea interaction over the global oceans. J Clim 15(16):2205-2231

Bagley JE, Desai AR, Harding KJ, Snyder PK, Foley JA (2014) Drought and deforestation: has land cover change influenced recent precipitation extremes in the amazon? J Clim 27(1):345-361

Balmaseda MA, Trenberth KE, Källén E (2013) Distinctive climate signals in reanalysis of global ocean heat content. Geophys Res Lett 40(9): 1754-1759

Ban-Weiss GA, Caldeira K (2010) Geoengineering as an optimization problem. Environ Res Lett 5(3):034009

Belikov DA, Bril A, Maksyutov S, Oshchepkov S, Saeki T, Takagi H et al (2014) Column-averaged co2 concentrations in the subarctic from GOSAT retrievals and NIES transport model simulations. Polar Sci 8(2):129-145

Bjerknes J (1966) A possible response of the atmospheric Hadley circulation to equatorial anomalies of ocean temperature. Tellus 18(4):820-829

Bonan GB (2008) Forests and climate change: forcings, feedbacks, and the climate benefits of forests. Science 320(5882):1444-1449

Bonan GB (1999) Frost followed the plow: impacts of deforestation on the climate of the United States. Ecol Appl 9(4):1305-1315

Bonan GB, Pollard D, Thompson SL (1992) Effects of boreal forest vegetation on global climate. Nature 359(6397):716-718
Bond NA, Harrison DE (2000) The pacific decadal oscillation, air-sea interaction and central north pacific winter atmospheric regimes. Geophys Res Lett 27(1):731-734

Bright RM, Cherubini F, Strømman AH (2012) Climate impacts of bioenergy: inclusion of carbon cycle and albedo dynamics in life cycle impact assessment. Environ Impact Assess Rev 37(37):2-11

Brovkin V, Ganopolski A, Claussen M, Kubatzki C, Petoukhov V (1999) Modelling climate response to historical land cover change. Glob Ecol Biogeogr 8(6):509-517

Cavalieri DJ, Gloersen P, Parkinson CL, Comiso JC, Zwally HJ (1997) Observed hemispheric asymmetry in global sea ice changes. Science 278(5340):1104-1106

Chambers DP, Tapley BD, Stewart RH (1999) Anomalous warming in the Indian Ocean coincident with El Niño. J Geophys Res Oceans 104(C2):3035-3047

Charney JG (1975) Dynamics of deserts and drought in the Sahel. Q J R Meteorol Soc 101(428):193-202

Charney J, Quirk WJ, Chow SH, Kornfield J (1977) A comparative study of the effects of albedo change on drought in semi-arid regions. J Atmos Sci 34:9

Chase TN, Pielke RA, Kittel S et al (2000) Simulated impacts of historical land cover changes on global climate in northern winter. Clim Dyn 16(2):93-105

Chase TN, Pielke RA, Kittel TGF, Nemani R, Running SW (1996) Sensitivity of a general circulation model to global changes in leaf area index. J Geophys Res Atmos 101(D3):7393-7408

Chen B, Xu G, Coops NC, Ciais P, Myneni RB (2016) Satelliteobserved changes in terrestrial vegetation growth trends across the Asia-Pacific region associated with land cover and climate from 1982 to 2011. Int J Digit Earth 9(11):1055-1076

Comiso JC, Nishio F (2008) Trends in the sea ice cover using enhanced and compatible AMSR-E, SSM/I, and SMMR data. J Geophys Res Oceans 113(C2):C02S07

Cracknell AP (2001) The exciting and totally unanticipated success of the AVHRR in applications for which it was never intended. Adv Space Res 28(1):233-240

Crisp D (2004) Orbiting carbon observatory (OCO). Adv Space Res 34(4):700-709

Crisp D, Fisher BM, O’Dell C, Frankenberg C, Basilio R, Bösch H et al (2012) The acos $\mathrm{CO}_{2}$ retrieval algorithm—part II: global data characterization. Atmos Meas Tech 5(4):687-707

Defries RS, Townshend JRG (1994) NDVI-derived land cover classifications at a global scale. Int J Remote Sens 15(17):3586-3675

Deser C, Magnusdottir G, Saravanan R, Phillips A (2004) The effects of North Atlantic SST and sea ice anomalies on the winter circulation in CCM3. Part II: direct and indirect components of the response. J Clim 17(5):877-889

Fang Y (2013) Projected impacts of bioenergy-demand-induced land use and cover changes on regional climate in Central Europe. Adv Meteorol 293937:1-9

Friedlingstein P (2014) Uncertainties in CMIP5 climate projections due to carbon cycle feedbacks. J. Climate 27(2):511-526

Gent PR, Danabasoglu G, Donner LJ et al (2011) The community climate system model version 4. J Clim 24:4973-4991

Govindasamy B, Duffy PB, Caldeira K (2000) Land use changes and northern hemisphere cooling. Geophys Res Lett 28(2):291-294

Guan Z, Yamagata T (2003) The unusual summer of 1994 in East Asia: IOD teleconnections. Geophys Res Lett 30(10):235-250

Harper K, Yue X, Unger N (2016) Climate and air quality impacts of altered BVOC fluxes from land cover change in Southeast Asia 1990-2010. EGU General Assembly Conference (Vol. 18). EGU General Assembly Conference Abstracts

Hendersonsellers A, Mcguffie K, Gross C (1995) Sensitivity of global climate model simulations to increased stomatal resistance and $\mathrm{CO}_{2}$ increases. J Clim 8(January):1738-1756 
Herman GF, Johnson WT (1978) The sensitivity of the general circulation to arctic sea ice boundaries: a numerical experiment. Mon Weather Rev 106(12):1649-1664

Houghton RA, Hobbie JE, Melillo JM, Moore B, Peterson BJ (1983) Changes in the carbon content of terrestrial biota and soils between 1860 and 1980: a net release of $\mathrm{CO}_{2}$ to the atmosphere. Ecol Monogr 53(3):236-262

Hurrell JW (1996) Influence of variations in extratropical wintertime teleconnections on northern hemisphere temperature. Geophys Res Lett 23(6):665-668

Idso S (1983) Carbon dioxide: friend or foe. J Ecol 72(1):355

IPCC (2000) Special report on emissions, working group III, intergovernmental panel on climate change. Cambridge University Press, Cambridge

Jacobson MZ, Kaufman YJ, Rudich Y (2007) Examining feedbacks of aerosols to urban climate with a model that treats 3 -D clouds with aerosol inclusions. J Geophys Res 112:D24205

Keshavamurty RN (1982) Response of the atmosphere to sea surface temperature anomalies over the equatorial Pacific and the teleconnections of the Southern oscillation. J Atmos Sci 39(6):1241-1259

King JC, Turner J (1997) Antarctic meteorology and climatology

Latif M, Barnett TP (1994) Causes of decadal climate variability over the north pacific and North America. Science 266(5185):634-637

Li S, Lu J, Huang G, Hu K (2008) Tropical Indian Ocean basin warming and East Asian summer monsoon: a multiple AGCM study. J Clim 21(22):6080

Liang XS (2013) Local predictability and information flow in complex dynamical systems. Physica D 248:1-15

Liang XS (2014) Unraveling the cause-effect relation between time series. Phys Rev E Stat Nonlinear Soft Matter Phys 90(5-1):052150

Liang XS (2015) Normalizing the causality between time series. Phys Rev E 92(2):022126

Liang, X. S. (2016). Information flow and causality as rigorous notions ab initio. Phys. Rev. E, 94(5), 052201, 1-28

Liang XS (2018) Causation and information flow with respect to relative entropy. Chaos 28(7):075311

Lim EP, Hendon HH, Arblaster JM et al (2016) Interaction of the recent 50 year SST trend and La Niña 2010: amplification of the Southern Annular Mode and Australian springtime rainfall. Clim Dyn 47(7-8):1-19

Lim KSS, Leung LR, Ma PL, Singh B, Zhao C, Zhang Y et al (2014) Investigation of aerosol indirect effects using a cumulus microphysics parameterization in a regional climate model. J Geophys Res Atmos 119(2):906-926

Liu X, Yin ZY (2001) Spatial and temporal variation of summer precipitation over the eastern Tibetan Plateau and the North Atlantic Oscillation. J Clim 14(13):2896-2909

Manabe S, Wetherald RT (1980) On the distribution of climate change resulting from an Increase in $\mathrm{CO}_{2}$ content of the atmosphere. $\mathrm{J}$ Atmos Sci 37(3):99-118

Manabe S, Wetherald RT, Stouffer RJ (1981) Summer dryness due to an increase of atmospheric $\mathrm{CO}_{2}$ concentration. Clim Change 3(4):347-386

Meehl GA, Arblaster JM, Fasullo JT, Hu A, Trenberth KE (2011) Model-based evidence of deep-ocean heat uptake during surfacetemperature hiatus periods. Nat Clim Change 1(7):360-364

Meehl GA, Hu A, Arblaster JM, Fasullo J, Trenberth KE (2013) Externally forced and internally generated decadal climate variability associated with the interdecadal Pacific Oscillation. J Clim 26(18):7298-7310

Namias J (1969) Seasonal interactions between the North Pacific Ocean and the atmosphere during the 1960's. Mon Weather Rev 97(3):173
Namias J, Yuan X, Cayan DR (1988) Persistence of north pacific sea surface temperature and atmospheric flow patterns. J Clim 1(7):682-703

Neale RB, Richter JH, Conley AJ, et al (2010) Description of the NCAR community atmosphere model (CAM 4.0). Technical Note NCAR/TN-485 + STR

Neale RB, Richter JH, Jochum M (2008) The impact of convection on ENSO: from a delayed oscillator to a series of events. J Clim 21(22):5904-5924

Oleson KW, Lawrence DM, Bonan GB, et al (2010) Technical description of version 4.0 of the Community Land Model (CLM). NCAR Technical Note NCAR/TN-478 + STR

Parkinson CL, Cavalieri DJ, Gloersen P et al (1999) Arctic sea ice extents, areas, and trends, 1978-1996. J Geophys Res Oceans 104(19):20837-20856

Pavia EG, Graef F, Reyes J (2006) PDO ENSO effects in the climate of Mexico. J Clim 19(24):6433-6438

Pettorelli N, Vik JO, Mysterud A, Gaillard JM, Tucker CJ, Stenseth NC (2005) Using the satellite-derived NDVI to assess ecological responses to environmental change. Trends Ecol Evol 20(9):510

Potter GL, Cess RD (1984) Background tropospheric aerosols: incorporation within a statistical-dynamical climate model. J Geophys Res Atmos 89(D6):9521-9526

Rasmusson EM, Wallace JM (1983) Metrological aspects of the El Niño/Southern oscillation. Science 222(4629):1195-1202

Reuter M, Bovensmann H, Buchwitz M, Burrows JP, Connor BJ, Deutscher NM et al (2011) Retrieval of atmospheric $\mathrm{CO}_{2}$ with enhanced accuracy and precision from SCIAMACHY: validation with FTS measurements and comparison with model results. J Geophys Res Atmos 116(D4):220-237

Reynolds RW, Rayner NA, Smith TM, Stokes DC, Wang W (2002) An improved in situ and satellite SST analysis for climate. J Clim 15(2002):1609-1625

Richter JH, Rasch PJ (2008) Effects of convective momentum transport on the atmospheric circulation in the community atmosphere model, version 3. J Clim 21(21):1487-1499

Robinson WA (2003) Dynamical nonlinearity in the atmospheric response to Atlantic sea surface temperature anomalies. Geophys Res Lett 30(20):2038

Rogers JC, Loon HV (1979) The seesaw in winter temperatures between Greenland and northern Europe. Part II: some oceanic and atmospheric effects in middle and high latitudes. Monthly Weather Rev 107(5):509

Ropelewski CF, Halpert MS (1987) Global and regional scale precipitation patterns associated with the El Niño/Southern oscillation. Mon Weather Rev 115(8):1606-1626

Rotty RM (1983) Distribution of and changes in industrial carbon dioxide production. J Geophys Res Oceans 88(C2):1301-1308

Seneviratne SI, Donat MG, Pitman AJ, Knutti R, Wilby RL (2016) Allowable $\mathrm{CO}_{2}$ emissions based on regional and impact-related climate targets. Nature 529(7587):477

Snyder PK, Delire C, Foley JA (2004) Evaluating the influence of different vegetation biomes on the global climate. Clim Dyn 23(3-4):279-302

Stips A, Macias D, Coughlan C, Garciagorriz E, Liang XS (2016) On the causal structure between $\mathrm{CO}_{2}$ and global temperature. Sci Rep 6:21691

Sud YC, Smith WE (1985) The influence of surface roughness of deserts on the July circulation. Bound-Layer Meteorol 33(1): $15-49$

Sutton RT (2000) The North Atlantic oscillation-what role for the ocean? Atmos. Sci. Lett. 1(2):89-100

Thompson DWJ, Wallace JM (2000) Annular modes in the extratropical circulation. Part I: month-to-month variability. J Clim 13(5):1000-1016 
Trenberth KE (1990) Recent observed interdecadal climate changes in the northern hemisphere. Bull Am Meteor Soc 71(7):377-390

Tucker CJ (1979) Red and photographic infrared linear combinations for monitoring vegetation. Remote Sens Environ 8(2):127-150

Wang B, Wu R, Fu X (2000) Pacific-east Asian teleconnection: how does ENSO affect east Asian climate? J Clim 13(9):1517-1536

Wang C, Liu H, Sang-Ki L (2010) The record-breaking cold temperatures during the winter of 2009/2010 in the northern hemisphere. Atmos Sci Lett 11(3):161-168

Watanabe M, Kamae Y, Yoshimori M, Oka A, Sato M, Ishii M et al (2013) Strengthening of ocean heat uptake efficiency associated with the recent climate hiatus. Geophys Res Lett 40(12):3175-3179

Woodwell GM, Whittaker RH, Reiners WA, Likens GE, Delwiche CC, Botkin DB (1978) The biota and the world carbon budget. Science 199(4325):141-146

Wu A, Hsieh WW, Shabbar A (2005) The nonlinear patterns of North American winter temperature and precipitation associated with ENSO. J. Climate 18(11):1736-1752
Yang J, Liu Q, Xie SP, Liu Z, Wu L (2007) Impact of the Indian Ocean SST basin mode on the Asian summer monsoon. Geophys Res Lett 34(2):155-164

Zhang Y, Wallace JM, Battisti DS (1997) ENSO-like interdecadal variability. J Clim 10(5):1004-1020

Zhan R, Wang Y, Lei X (2011) Contributions of ENSO and East Indian Ocean SSTA to the interannual variability of Northwest Pacific tropical cyclone frequency. J Clim 24(2):509-521

Zhang GJ, Mcfarlane N (1995) Sensitivity of climate simulations to the parameterization of cumulus convection in the Canadian climate centre general circulation model. Atmosphere 33(3):407-446

Publisher's Note Springer Nature remains neutral with regard to jurisdictional claims in published maps and institutional affiliations. 